\title{
Service Quality, Value and Satisfaction in University Job Fair
}

\author{
Jung Yoon Kim \\ Change Management Center, NICE Group, Seoul, 150-010, Korea
}

Keum Lim Kim

\begin{abstract}
This paper examines the casual relations among service quality, perceived value and satisfaction from the perspective of Job Fair attendees. Numerous studies have been conducted in the field of perceived value and satisfaction. This work would be the mere contribution in the literature development but surely contribute to the better development of service providing sector to create better quality, value and satisfaction. A framework suggested that personal service, touristic attractiveness and physical environments were turned out to affect positively on the perceived value and satisfaction. The service providers should concentrate on developing the issues.
\end{abstract}

Keywords: SERVQUAL, Perceived Value, Satisfaction, Job Fair

\section{INTRODUCTION}

Due to an increasing number of young, unemployed graduates each year, it is becoming more difficult for university students to make their debut in society. Also, "Graduation equals Joblessness" is a popular saying around universities today, reflecting the severity of the unemployment problem. Thus, when choosing a college, students tend to decide on majors that have a higher rate of employment, without much consideration of their aptitude [1]. In addition to the decreasing of jobs among the youth, "decent jobs", traditionally occupied by holders of higher education, are also decreasing, due to the recession and changes in the forms of employment by major companies. This has caused the demand-supply mismatch in the labor market for the highly educated personals [2]. Therefore, universities are trying to solve the unemployment problem through various programs, offering employment support for students who wish to acquire jobs.

A part of the universities' employment program is a job fair, which provides benefits for both the students and the companies attending. The job fair is useful for students since it is easily accessible, and it provides them in-depth information about various companies. Furthermore, students can ease their vague anxieties about employment through consulting programs at the fair. Participating companies also find the job fair beneficial, for it can publicize and increase their value; the fair provides them with an opportunity to share their information and find more suitable employees on site.

Moreover, the job fair is a knowledge-based industry,

\footnotetext{
${ }^{*}$ Corresponding author. E-mail : jykimshan@hotmail.com Manuscript received Apr.23, 2010 ; accepted Jun. 07, 2010
}

providing appropriate information for the current time, as well as promoting the information circulation; it also has strong characteristics of human service industry. Hence, it is a characteristic of job fairs to require evaluation of the positive and negative results of their events.

This research theoretically exams the effects of the service quality of job fairs on the value and satisfaction perceived by the participants of the fair, and based on theoretical back ground, it will seek to verify the structural equation modeled on a casual relationship. The purpose of this research is first, to verify whether the service quality of the job fair affects the value and satisfaction perceived by the participants and second, to investigate the effects of value on satisfaction.

The results of this research are projected to assist hosts to prepare more effective job fairs, with deeper understanding on the views of the participants. It will also contribute to the enhancement of the perceived value of the attending companies, by helping them achieve improved service quality.

\section{THEORETICAL BACKGROUND}

\subsection{Service Quality, value, and customer satisfaction}

Service quality represents the consumer's perception on the service provided by a company or a group, and the importance of service quality has been discussed by many scholars [3]. Generally, service quality is a primary factor in deciding the service satisfaction. For example, consumers, experiencing satisfaction in the service provided, made repeated purchases or were found to be loyal to certain brands.

The perceived quality, according to Grönroos [4], is the consumer's subjective assessment of products or brands, with 
service quality, where the service quality is perceived by the understanding of the concept and meaning of the products or brands.

Generally, service quality is assessed in five different criteria: empathy, assurance, tangibility, responsiveness, and reliability. Later researchers compared and accessed the expected service and the actual service performed, by using the SERVQUAL model.

However, in this research, the five criteria of the SERVQUAL model are modified as an assurance of information, human service, accessibility, physical environment, and tourist attraction, to suit the purposes of the research.

Competition in today's market is rising more than ever, since the consumer's desire for products and services with value are growing, and various workers have different views on the value of the customer. Hence, it is important for service providers to faithfully play the role of representing the customers.

Rajendran \& Harharam [5] asserted that the perceived value is the greatest predictor in customer satisfaction, and that the manager and researchers should focus and research on understanding the preceding variable of the perceived value.

Value is a significant predictor of individual attitude and behavior, which affects not only the choice behavior of the customer, prior to purchasing, but also the customer's behaviors subsequent to the purchase, such as, customer satisfaction and returned visit.

However, when measuring perceived value, it can be difficult to conceptualize the value or to define its operation. One of the ways to alleviate this difficulty is to determine whether the measured value is realized in the present or in the future. If value is measured only in the present, within a limited range, where it is judged to have been formed from a one-time deal, errors can occur, where potential value is undermined and value is over or under rated. Thus, it is crucial to determine whether the value can be measured from a certain point in time or if it should continually be measured and assessed; methods for evaluation should be sought according to this determination.

In this research, the value of the cost properties, perceived by the participants of the job fair will be fabricated based on previous documents. Companies in current society set the achievement of customer satisfaction as their primary goal, and most of their activities surround in maximizing the customer satisfaction. Hence, many researchers have been working on this subject for a long time.

According to Oliver [6], customer satisfaction is a psychological condition, where the customer experiences something different from what was expected from the consumption. The most widely used theory for explaining the process of customer satisfaction is the Expectation Discrepancy Paradigm [6][7]. According to this paradigm, customers form certain expectations after consuming a product or a service, and customer satisfaction is determined when the customers compare their expectations with the actual performance of the product or service.

Companies with high customer satisfaction gain various advantages and benefits, such as, advancement in customer loyalty and financial profits, reduced price sensitivity, retention of existing customers, reduction of costs in marketing failures and in generating new customers, and the improvement of the company's overall image [8].

However, it is difficult to objectively measure the concept of satisfaction. Thus, the result of subjective judgment, through human psychological process, is used to measure satisfaction. A typical method of measuring satisfaction is to combine the satisfaction based on experience with the overall satisfaction from the items, in which the satisfaction and judgments are perceived.

Accordingly, in this research, in order to understand relative relationships affecting the perceived satisfaction, the following criteria are added in measuring satisfaction: satisfaction regarding service and satisfaction regarding physical environment. The two criteria will measure the perceived value of the participants at the job fair, detecting the affects of the physical components of the fair on the participants' emotional judgments, made through cognitive processing.

\subsection{The Relationship between perceived quality and value}

Regarding the causal relationship of service quality and value, Bonton and Drew [9] stated that the service quality works as the predictor in service value. This view is in the same context with what Lee and Kim [10] had found from their research on hotel customers nationwide; they had discovered that the service value was the mediator between service quality and customer satisfaction, causing the mediator effect.

Furthermore, Lee and Ulgado [11] presented that the consumers use the cancellation effect when judging the service value, counterbalancing the positive factor of service quality with the negative factor of paying the price. They also pointed out how the service value can be measured from the perceived difference between expectation and service result, where service quality, time, and price are the determining factors.

Another research, centered around fitness clubs, observed the causal relations among service quality, service value, customer satisfaction, and customer loyalty and found that the causal relation between service quality and value, positively affect empathy, assurance, tangibility, responsiveness, and reliability [12]. Moreover, Ghi and Lee [13] conducted a research on brand coffee shops, to study how perceived quality and brand image affects the perceived value and loyalty. In their research, the perceived quality was found to have positive effects on the perceived value and loyalty of the customers. The following hypotheses are made for this research, based on previously stated research findings.

Hypothesis 1: Perceived quality on the assurance of information will have a positive effect on value.

Hypothesis 2: Perceived quality on human service will have a positive effect on value.

Hypothesis 3: Perceived quality on accessibility will have a positive effect on value.

Hypothesis 4: Perceived quality on physical environment will have a positive effect on value.

Hypothesis 5: Perceived quality on tourist attraction will have a positive effect on value. 


\subsection{Relationship between perceived value and satisfaction}

Rajendran and Harharam [5] emphasized that the perceived value is the most important predictor and that the executives and the researchers should pay attention to understanding the antecedent of perceived value. Generally, value can be defined as an expected benefit or gain through products or services [14]. Value is perceived as an importance to consumers; value is an important preceding variable, which effects the consumers' actions before and after purchasing, including customer satisfaction and revisits. The following is a hypothesis of this study, based on preceding research, regarding the value and satisfaction perceived by the participants of the job fair.

Hypothesis 6: The value perceived by the participants of the job fair will have a positive effect on satisfaction.

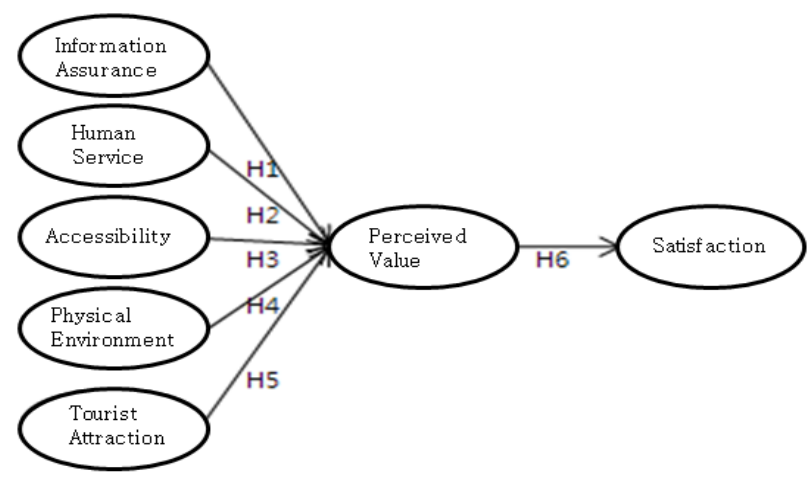

Fig. 1. Research Model

\section{METHODOLOGY}

Chung-Ang University has been annually hosting job fairs for the last four years. The following is a brief summary of the 2009 Job Fair's event size and content. Doosan, Samsung, and 48 other companies attended the job fair, and about 1500 people have signed the guest book. However, including those who did not sign, the number of participants greatly exceeds. Events at the job fair included: the Opening Ceremony, Recruitment Hall, Consulting Hall (Aptitude Test with fingerprint recognition, Cover Letter Clinic, Interview Image Consulting), Event Hall (Free Resume Photo Studio, Makeup Beauty Clinic, Job Fortune Event Hall), and presentation of mentos and raffle prizes (Nintendo, Electronic Dictionary, MP3, Culture gift certificate, etc.).

This research was done on the students and job seekers who attended the 2009 Job Fair at Chung-Ang University, which was held from September $3^{\text {rd }}$ to $4^{\text {th }}$ at the Seoul campus gymnasium. When the participants were exiting the fair, they were asked whether they received beneficial employment counseling at the fair. The research was also explained to them and then asked if they would like to participate; about 224 agreed to participate in the research. $100 \%$ of all answers by the 224 participants were used in the analysis.

The measurements were composed around the contents extracted from preceding researches [3]. For the perceived quality factors of the host city, 16 questions were asked, using a 5-Point Likert scale. The composition of the questions included: Assurance of Information (3 questions), Human Service (4 questions), Accessibility (3 questions), Physical Environment (2 questions), and Tourist Attraction (3 questions). Furthermore, a factor analysis was done to observe the validity of the concentrated variables and the distinct variables, and two questions, one from Human Service and another from Tourist Attraction, were eliminated while the remaining 14 questions were used for the analysis. For measuring the perceived value of the results, three questions were asked, using a 5-Point Likert scale. The questions asked pertained to the convention's support service and price value, the physical environment of the convention center, and the attractiveness of the city [15]. The resulting variable of this research, the satisfaction factor, was assessed with questions on overall physical environment, support service, and the price value, which are major factors affecting the continuity of the fair. There were three questions total, using a 5-Point Likert scale for measurement.

\section{RESULTS}

In this research, reliability of the measurements made on the research variables, are verified by finding the Cronbach's Alpha, based on an average correlation, since all data are standardized. Also, exploratory factor analysis and correlation analysis were conducted for the research variables' discriminant validity and analysis of relations. Furthermore, the research model used for the final analysis was tested with AMOS 4, for model structure testing. Thus, each hypothesis regarding the relationship between variables was tested, and the relevance of the model, including relations of all research variables, was confirmed.

\subsection{Research sample}

In order to analyze the sample's demographical characteristics and participants' information, this study used descriptive statistics analysis and frequency analysis.

There were 244 participants who responded to the survey, with 107 men (47.8\%) and 117 women (52.2\%). According to the demographic variables and characteristics of participation, the desire to participate in social activities appeared to be higher among women.

The number of interviews, which the participants took with the partaking companies, showed the participants' enthusiasm towards employment. 65 participants $(29.0 \%)$ had one interview, 54 participants $(24.1 \%)$ had three interviews, 37 participants $(16.5 \%)$ had two interviews, 29 participants (12.9\%) had four interviews, 18 participants $(8.0 \%)$ had five interviews, and 21 participants $(9.4 \%)$ had over six interviews.

Also, for the number of job fairs attended by the participants over the last year, including the job fair of this research, the majority of 146 participants $(65.2 \%)$ attended one, 62 participants (27.7\%) attended from two to three, 11 participants attended from four to five job fairs, and 5 participants (2.2\%) 
attended over six job fairs. Moreover, most of the participants were Chung-Ang University students, and for the majority, this job fair was their first time attending.

Observing the number of job fair participations for the last three years, including this event, the highest percentage of the participants, 87 people $(38.8 \%)$, had attended job fairs two to three times. Next, 86 participants $(38.4 \%)$ had attended only once, 15 participants $(6.7 \%)$ had attended four to five times, 11 participants $(4.9 \%)$ had attended over six times, and 25 participants $(11.2 \%)$ attended more or less or do not know (other).

For counseling, the field of management/clerical / accounting / marketing had the most participants with 55 people $(24.6 \%)$. The next most popular field was the financial business/construction industry, with 45 participants (20.1\%). Counseling for information and communication enterprise had 42 people $(18.8 \%)$, and 27 people $(12.1 \%)$ participated in the counseling for the service industry/distribution industry. Counseling for professional/specialized/·education had 20 people $(8.95 \%)$ participating. Counseling for primary industry/manufacturing industry had 15 participants $(6.7 \%)$, business/sales/TM.CS had 14 participants (6.3\%), and service/·event/·travel had 6 participants $(2.7 \%)$.

\subsection{Exploratory Factor Analysis}

In order to measure the service quality perceived by the participants of the job fair, this research used the following five variables: assurance of information, human service, accessibility, physical environment, and tourist attractions.

Table 1. Factor Analysis Table of Total Study Unit

\begin{tabular}{|c|c|c|c|c|c|c|c|}
\hline Item & Factor1 & Factor2 & Factor3 & Factor4 & Factor5 & Factor6 & Factor7 \\
\hline Human-S8 & 0.842 & 0.135 & 0.155 & 0.190 & 0.143 & 0.134 & 0.063 \\
\hline Human-S10 & 0.804 & 0.281 & 0.149 & 0.112 & 0.131 & 0.031 & 0.192 \\
\hline Human-S9 & 0.782 & 0.201 & 0.239 & 0.148 & 0.187 & 0.029 & 0.154 \\
\hline Human-S7 & 0.636 & 0.256 & 0.385 & 0.170 & 0.185 & -0.058 & 0.000 \\
\hline In-depth2 & 0.277 & 0.841 & 0.057 & 0.083 & 0.074 & 0.145 & 0.069 \\
\hline Purpose3 & 0.143 & 0.833 & 0.085 & 0.185 & 0.153 & 0.042 & 0.067 \\
\hline Friendly1 & 0.222 & 0.814 & 0.072 & 0.132 & 0.189 & -0.002 & 0.187 \\
\hline Access2 & 0.119 & 0.121 & 0.882 & 0.051 & 0.086 & 0.031 & 0.153 \\
\hline Access1 & 0.259 & -0.016 & 0.830 & -0.032 & 0.149 & 0.012 & -0.058 \\
\hline Access3 & 0.196 & 0.084 & 0.817 & 0.155 & 0.065 & -0.022 & 0.161 \\
\hline Value1 & 0.193 & 0.165 & 0.058 & 0.801 & 0.241 & 0.220 & 0.167 \\
\hline Value2 & 0.144 & 0.152 & 0.097 & 0.773 & 0.189 & 0.250 & 0.266 \\
\hline Value3 & 0.257 & 0.181 & 0.057 & 0.727 & 0.412 & 0.130 & 0.059 \\
\hline Satisfaction2 & 0.307 & 0.212 & 0.212 & 0.311 & 0.740 & 0.091 & 0.058 \\
\hline Satisfaction1 & 0.177 & 0.125 & 0.085 & 0.246 & 0.728 & 0.291 & 0.243 \\
\hline Satisfaction3 & 0.194 & 0.279 & 0.211 & 0.395 & 0.694 & 0.104 & 0.189 \\
\hline Tour12 & 0.123 & 0.089 & 0.085 & 0.203 & 0.087 & 0.843 & 0.134 \\
\hline Tour13 & -0.035 & 0.048 & -0.089 & 0.183 & 0.189 & 0.825 & 0.164 \\
\hline Physical4 & 0.136 & 0.094 & 0.245 & 0.275 & 0.107 & 0.243 & 0.795 \\
\hline Physical 5 & 0.229 & 0.288 & 0.049 & 0.174 & 0.298 & 0.192 & 0.713 \\
\hline $\begin{array}{c}\text { Total } \\
\text { Variance }\end{array}$ & 3.013 & 2.612 & 2.590 & 2.447 & 2.171 & 1.766 & 1.547 \\
\hline Variance & 15.065 & 13.061 & 12.952 & 12.233 & 10.856 & 8.831 & 7.735 \\
\hline $\begin{array}{c}\text { Cumulative } \\
\text { Variance }\end{array}$ & 15.065 & 28.126 & 41.078 & 53.311 & 64.167 & 72.997 & 80.732 \\
\hline Reliability & 0.891 & 0.871 & 0.857 & 0.884 & 0.879 & 0.735 & 0.778 \\
\hline
\end{tabular}

Also, for the result variable of service quality, value and satisfaction are laid out. Also, the measurement model was verified through explorative factor analysis, verifying the variables' validity of concept.

As seen on [Table 1], of the factor analysis table for the total study unit, only factor 7 in human service and factor 3 on satisfaction have values from 0.636 to 0.694 ; all other factors have exceeded 0.7 . Also, the cumulative variance of the total study unit is 80.732 , and the reliability of the study units are all over 0.735 as well. Hence, these units were verified and were used in the study as measuring units, for they had convergent validity and questions with internal consistency reliability.

\subsection{Correlation Analysis and Structure Model Analysis}

The results of the correlation analysis of the variables used in this study are shown on [Table 2]. According to the results shown on table 1 , the discriminant validity is secured, for the correlation coefficients among variables are all under 0.7. This satisfies the standard proposed by Kline [16], where correlation coefficients under 0.85 are verified to have discriminant validity.

Table 2. Variables' descriptive statistics and correlation

\begin{tabular}{|c||c|c||c|c|c|c|c|c|}
\hline Variables & Mean & SD & 1 & 2 & 3 & 4 & 5 & 6 \\
\hline $\begin{array}{c}\text { 1.Information } \\
\text { Assurance }\end{array}$ & 4.362 & 1.077 & 1.000 & & & & & \\
\hline 2.Accessibility & 4866 & 1.031 & 0.238 & 1.000 & & & & \\
\hline $\begin{array}{c}\text { 3.Human } \\
\text { Service }\end{array}$ & 4.789 & 1.018 & 0.538 & 0.504 & 1.000 & & & \\
\hline $\begin{array}{c}\text { 4.Physical } \\
\text { Environment }\end{array}$ & 4.107 & 1.175 & 0.437 & 0.341 & 0.464 & 1.000 & & \\
\hline $\begin{array}{c}\text { 5.Tourist } \\
\text { Attraction }\end{array}$ & 3.455 & 1.325 & 0.220 & 0.068 & 0.188 & 0.484 & 1.000 & \\
\hline 6.Value & 4.186 & 1.059 & 0.443 & 0.252 & 0.498 & 0.583 & 0.494 & 1.000 \\
\hline 7.Satisfaction & 4.174 & 1.157 & 0.501 & 0.381 & 0.568 & 0.581 & 0.427 & 0.730 \\
\hline ** : p<.01. * : $\mathrm{p}<0.05$, Result of the two-sided test \\
\hline
\end{tabular}

Furthermore, in order to prove the hypothesis of this research, a structural equation model analysis was implemented. In general, for testing the suitability of the structure in the structural equation model, indicators, such as, GFI, AGFI, NFI, RMSEA are used. Coefficients over 0.9 is said to be best, when using GFI, AGFI, and NFI, and over 0.05 is the ideal coefficient when using the RMSEA indicator. The structure used for this study passed the suitability test, with GFI $=0.901$, $\mathrm{NFI}=0.915$, and RMSEA 0.059 .

Also, the value of chi-square is not interpreted as the measurement for a suitability test; instead, the value of the samples' size and chi-square (260.829) is divided by (146) degree of freedom, which came out to be 1.787 , securing the safety of the sample for it is lower than 3 .

Looking at the results of the hypothesis test, the path coefficient for the test on the effects of the information assurance on perceived value came out to be 0.123 , with $\mathrm{t}=1.522$. Thus, hypothesis number 1 was rejected. Furthermore, hypothesis number 2 was also rejected, for the path coefficient for the test on the effects of accessibility on the perceived value 
was -0.009 with $t=0.117$. Conversely, hypothesis number 3 was accepted since the path coefficient for the effects of human service on the perceived value was 0.306 , with $t=3.267$ and $\mathrm{p}<0.05$. Hypothesis number 4 was also accepted because the path coefficient for the effects of physical environment on the perceived value was 0.308 with $\mathrm{t}=2.389$ and $\mathrm{p}<0.05$. Moreover, hypothesis number 5 was accepted given that the path coefficient for the effects of tourist attraction on the perceived value was 0.307 with $t=3.141$ and $p<0.05$. Lastly, hypothesis number 6 was accepted since the path coefficient for the effects of the perceived value on satisfaction was 0.894 with $t=12.395$ and $\mathrm{p}<0.01$.

[Figure 2] and [Table 3] show the organized results of the research model.

Table 3. Test Results of the Structural Equation Model

\begin{tabular}{c|c|c|c|c|c}
\hline \multicolumn{2}{l|}{ Path } & $\begin{array}{c}\text { Regression } \\
\text { Coefficient }\end{array}$ & $\begin{array}{c}\text { Standard } \\
\text { Error }\end{array}$ & C.R. & Result \\
\hline H1 & $\begin{array}{c}\text { Information Assurance } \\
\rightarrow \text { Value }\end{array}$ & 0.123 & 0.081 & 1.522 & Rejected \\
\hline $\mathrm{H} 2$ & $\begin{array}{c}\text { Human Service } \\
\rightarrow \text { Value }\end{array}$ & 0.306 & 0.094 & 3.267 & Accepted \\
\hline $\mathrm{H} 3$ & Accessibility $\rightarrow$ Value & -0.009 & 0.076 & -0.117 & Rejected \\
\hline $\mathrm{H} 4$ & $\begin{array}{c}\text { Physical Environment } \\
\rightarrow \text { Value }\end{array}$ & 0.308 & 0.129 & 2.389 & Accepted \\
\hline $\mathrm{H} 5$ & $\begin{array}{c}\text { Tourist Attraction } \\
\rightarrow \text { Value }\end{array}$ & 0.307 & 0.098 & 3.141 & Accepted \\
\hline H6 & Value $\rightarrow$ Satisfaction & 0.894 & 0.072 & 12.395 & Accepted \\
\hline \multicolumn{4}{c|}{ CMIN=358.172, df $=158$, GFI $=0.866$, AGFI $=0.821$, IFI=0.931, } \\
CFI=0.931, RMSEA $=0.075$
\end{tabular}

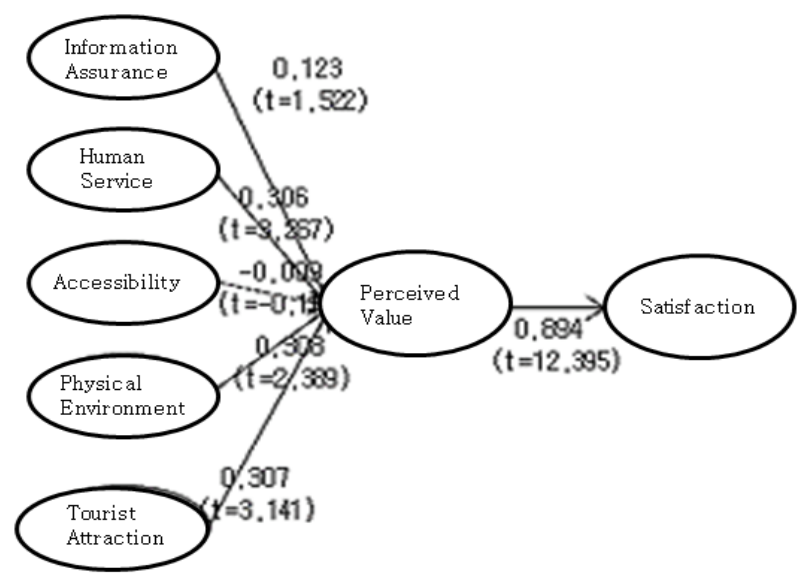

Fig. 2. Research Model Results

\section{CONCLUSION}

Aligning the results of the hypothesis in the order of the regression coefficients, the tourist attraction had the most effect on value; human service had the second most effect on value, and physical environment came third.

It is ironic how the tourist attraction was the greatest effecting variable on the perceived value of the participants of the job fair, when usually the participants of job fairs seem to pursue more practical values, such as employment help. Also, human service and assurance of information was predicted to be important; however, the tourist attraction and human service had similar importance according to the results. The next most important variable was the physical environment. Such results were possible since many people gather at job fairs; thus, tourist infrastructure and human service would be important factors for perceived value.

Tourist infrastructure and human service seem to have been viewed as important factors for perceived value since one of the characteristics of job fairs is that it gathers many people. Hence, the physical environment of the place, where the information is provided, was also viewed as an important factor in perceived value. Furthermore, such results portray how the participants, who have come for practical employment needs, still desire to obtain information and consulting in a pleasant environment.

Furthermore, in the hypothesis, the assurance of information was predicted to be an important variable in perceived value. However, its effect was minimal, according to the results of this study, since the companies that attended the job fair were mainly the nation's leading companies, where many already perceived them reliable for information assurance.

Also, accessibility, though it is an important factor for perceived value in all events [1][14], did not affect this study, for the job fair took place inside the university and most of the participants were its students; thus, it seems that the accessibility was not recognized as an issue for perceived value.

The current study contains a number of limitations that should be taken into account when interpreting the research findings. First of all, the study's sample was collected from a single 2009 Job Fair at Chung-Ang University. The second research limitation involves the number of sample. The number of sample is 244, which are not enough size for the Structure Model Analysis with 7 variables. The both research limitations above could reject the Hypothesis 1 and 3 (the impact of information assurance and accessibility on perceived value). Future studies need to extend the relationship to other job affairs. Moreover, future studies should collect larger samples in order to make the research results sable.

In general, the regression coefficient and $t$-value are proportional. However, this study showed an exceptional case, where the regression coefficient and t-value did not have a proportional relationship: the regression coefficient and t-value from the effects of tourist attraction and human service on perceived value, did not have proportional relationship to each other, although their values were close.

Similar to preceding studies [1][14][17][8], this research showed that the perceived value had a positive effect on satisfaction. This study also proposes that in order for the host of the job fair to raise the participants' satisfaction level, a managerial and strategic approach would be needed to improve the level of tourist attraction, human service, and physical environment, which affect the participants' perceived value. In addition, future research should implement a wider range of studies, comparing the service quality and perceived value, according to characteristics of the events. 


\section{REFERENCES}

[1] W.J. Kang, J.I. Kim and J.W. Kim, "A study on the analyses and effectiveness of the job search supporting programs by universities," Korean Academy of Human Resource Management, vol. 15, no. 1, 2007, pp. 17-36.

[2] J.Y. Suh, Analyses of Relationship Between the Employment Insecurity and The Standard of Selecting Workplace of Senior Students, Graduate School of Kyunggy University, 2007.

[3] A. Parasuraman, V.A. Zeithaml and L.L. Berry, "SERVQUAL : a multi-item scale for measuring consumer perception of service quality," Journal of Retailing, vol. 64, no. 1, 1988, pp. 13-30.

[4] C. Grönroos, "An applied service marketing theory," European Journal of Marketing, vol. 16, no. 7, 1993, pp. $30-41$.

[5] K.N. Ragendran and H.S. Hariharan, "Understanding Value: the role of consumer preferences," Journal of Marketing Management, vol. 17, 1996, pp.525-537.

[6] R.L. Oliver, "Measurement and evaluation of satisfaction process in retail setting," Journal of Retailing, vol. 67, Fall, 1981, pp. 25-48.

[7] R.A. Spreng, S.S. MacKenzie and R.W. Olshavsky, "A reexamination of the determinants of consumer satisfaction," Journal of Marketing, vol. 60, no. 3, 1996, p. 15-32.

[8] C. Fornell, "A National Customer Satisfaction Barometer: The Swedish Experience," Journal of Marketing, vol. 56, no. 1, 1992, pp. 6-21.

[9] R.N. Boston and H.D. James, "A Multistage Model of Consumers`Assessments of Service Quality and Value," Journal of Consumer Research, vol. 17, 1991, pp. 375384.

[10] H.S. Lee and Y. Kim., "Service Quality and Service Value," Korean Journal of Marketing, vol. 1, no. 2, 1999, pp.77-99.

[11] M.K. Lee and F.M. Ulgado, "Customer Evaluation of Fast-food Services : a Cross-national Comparison," Journal of Service Marketing, vol. 11, no.1, 1997, pp. 3952.

[12] J.H. Park, "The relationship Fitness Club of service quality and service value, customer satisfaction and customer loyalty," The Korean Journal of Physical Education, vol. 45, no. 5, 2006, pp. 301-311.

[13] M.O. Ki and D.I. Lee, "Influence of Perceived Quality and Brand Image on the Perceived Value and Loyalty in Specialty Coffee Shop -Moderating Role of the Consumer Knowledge," Journal of Foodservice Management, vol. 11, no. 3, 2008, pp. 49-72.

[14] Y.J. Lee, "A Theoretical Examination of Customer Satisfaction Research: Findings and Outlook," Journal of Consumer Studies, vol. 11, no. 2, 2000, pp. 139-166.

[15] H.Z. Al-Sabbahy, Y. Ekinci and M. Riley, “An Investigation of Perceived Value Dimensions: Implications for Hospitality Research," Journal of Travel Research, vol. 42, no. 3, 2004, pp.226-234.
[16] R.B. Kline, Principles and practice of structural equation modeling. NY : Guilford Press. Covers confirmatory factor analysis using SEM techniques. See esp. Ch. 7, 1998.

[17] R.I. Allison and K.O. Uhl, "Influence of beer brand identification on taste perception," Journal of Marketing Research, vol. 64, no. 1, 1964, pp. 36-39.

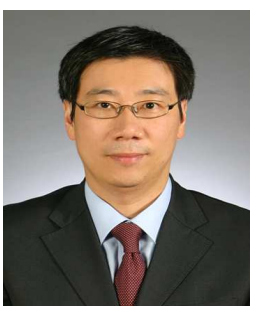

\section{Kim, Jung Yoon}

$\mathrm{He}$ received the B.S., M.S in business administration from Sogang university, Korea in 1992, 1994 respectively and also received Ph.D. in business administration from Loughborough university, UK in 2003. Since then, he had worked for Hyundai Motor Company between 2003 and 2009. He has been with NICE group. His main research interests include global organizational structure and new product development.

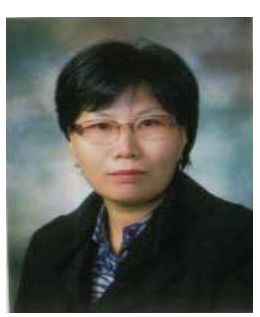

Kim, Keum Lim

She received the Ph.D. from Dongkuk university, Korea in 2009. 